\title{
A Review of the Radio Frequency Non-destructive Testing for Carbon-fibre Composites
}

\author{
Zhen $\mathrm{Li}^{1}$, Zhaozong Meng ${ }^{2}$ \\ ${ }^{1}$ School of Materials, The University of Manchester, Manchester, M13 9PL, UK, zhen.li-6@postgrad.manchester.ac.uk \\ ${ }^{2}$ School of Electrical and Electronic Engineering, The University of Manchester, Manchester, M13 9PL, UK
}

\begin{abstract}
The purpose of this paper is to review recent research on the applications of existing non-destructive testing (NDT) techniques, especially radio frequency (RF) NDT, for carbon-fibre reinforced plastics (CFRP) composites. Electromagnetic properties of CFRP composites that are associated with RF NDT are discussed first. The anisotropic characteristic of the conductivity and the relationship between the penetration depth and conductivity should be paid much attention. Then, the well-established RF NDT including eddy current technique, microwave technique and RF-based thermography are well categorised into four types (i.e. electromagnetic induction, resonance, RFbased thermography and RF wave propagation) and demonstrated in detail. The example of impact damage detection using the induction and resonance methods is given. Some discussions on the development (like industrial-scale automated scanning, three-dimensional imaging, short-range ultra-wideband (UWB) imaging and the radio frequency identification technology (RFID)-based NDT) are presented.
\end{abstract}

Keywords: Radio frequency (RF), non-destructive testing (NDT), carbon-fibre reinforced plastics (CFRP) composites, eddy current technique, microwave imaging, thermography.

\section{INTRODUCTION}

Carbon-fibre reinforced plastics composites (CFRP) have been widely used in aerospace, shipping and automotive structural applications, due to their superior stiffness and strength characteristics, fatigue and corrosion resistance [1]. However, due to continuous use and exposure to impact events, the performance of composite structures can be easily affected. Some kinds of manufacturing defects and inservice damage cannot be identified or evaluated by common visual observation. Therefore, various nondestructive testing (NDT) techniques have been applied to identify defects and damage, such as, acoustic emission, ultrasonic testing, eddy current, thermography, shearography, vibration testing, X-ray tomography, optical fibre sensors, Lamb waves, terahertz imaging and microwave techniques. Each NDT method has its own particular advantages, disadvantages and applications. A suitable selection among all the NDT methods for a specific case is up to the users. Some aspects (i.e., types of damage to be monitored, detection reliability, cost, portability, equipment setup, scanning time and safety concerns) must be well understood.

Among the existing NDT techniques, a group of radio frequency $(\mathrm{RF})$ techniques are receiving extensive attention in recent years, including eddy current, pulsed eddy current and microwave techniques. The frequency of interest is in the range of around $3 \mathrm{kHz}$ to $300 \mathrm{GHz}$ which occupies the lower range of the whole electromagnetic (EM) spectrum. The instrumentation becomes complicated, when the inspection frequency goes above $300 \mathrm{GHz}$ [2]. There are a number of attributes when applying the RF NDT, such as non-contact, one-sided scanning, no need for transducers or couplants, little safety hazard, etc.

This paper first presents the electromagnetic properties of carbon-fibre composites, and then reviews the mechanisms and applications of the existing RF NDT methods. The advantages and limitations of each approach for damage detection are addressed. An example of the detection of the representative barely visible impact damage (BVID) on a CFRP sample using three approaches is shown. Finally, some viewpoints on the development of NDT methods for industrial applications are given.

\section{ELECTROMAGNETIC PROPERTIES OF CARBON FIBRE COMPOSITES}

\section{A. Introduction}

The magnetic permeability $\mu$ of the carbon fibre composite material is equal to that of the free space $\mu_{0}$ (i.e. $\left.4 \pi \times 10^{-7} \mathrm{H} \cdot \mathrm{m}^{-1}\right)$, as the CFRP is nonmagnetic. The CFRP composites cannot be well described by the permittivity $\varepsilon$, as they are conductive rather than dielectric [3]. Hence, the discussion on the EM properties of the CFRP is mainly focused on its conductivity. 


\section{B. Anisotropic characteristic of the conductivity}

The electrical conductivity of the CFRP is anisotropic, as it is made up of electrically conductive carbon fibres embedded in the nonconductive resin. For a unidirectional lamina, the anisotropic characteristic of the conductivity can be represented by (1), where $\sigma_{L}$ and $\sigma_{T}$ denote the conductivities in the direction parallel and transverse to the fibre direction, respectively. The conductivities along the transverse direction and through-thickness direction are assumed the same. The longitudinal conductivity $\sigma_{L}$ is significantly larger than the transverse conductivity $\sigma_{T}$.

$$
\bar{\sigma}=\left[\begin{array}{ccc}
\sigma_{L} & 0 & 0 \\
0 & \sigma_{T} & 0 \\
0 & 0 & \sigma_{T}
\end{array}\right]
$$

$\sigma_{L}$ can be approximated by the conductivity of the carbon fibre $\sigma_{f}$ and the fibre volume fraction $v_{f}$, which is expressed as [4]

$$
\sigma_{L} \approx v_{f} \sigma_{f}
$$

However, the transverse conductivity could not be readily obtained, as the rate of the current flow in that direction depends on the waviness of the fibres. When the fibres are bent, the random contact between adjacent fibres facilitates the current flow [5]. Therefore, the transverse conductivity is varied by different manufacturing and processing processes.

\section{Penetration depth}

Considering the effect of the lossy medium, the power of the EM signal decays exponentially through the thickness of the sample. The penetration depth, or skin depth, in conductive materials is defined as follows [3]:

$$
d_{p} \cong \sqrt{\frac{2}{\omega \mu \sigma}}
$$

Where $\omega=2 \pi f$ is the angular frequency, and $f$ is the operating frequency. $\sigma$ is the electrical conductivity of the material.

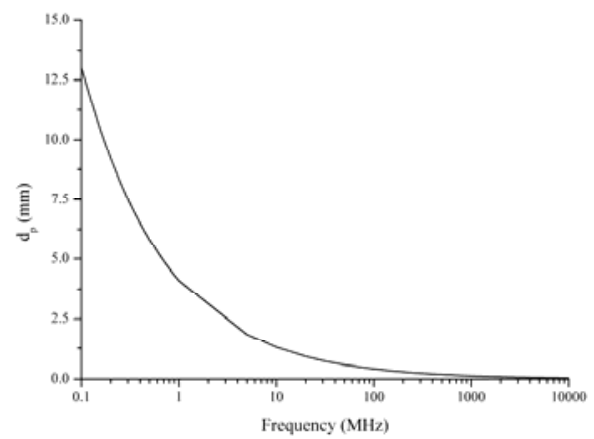

Fig.1. Variation of the penetration depth with respect to the frequency from $0.1 \mathrm{MHz}$ to $10 \mathrm{GHz}$.
The variation of the penetration depth for a carbon-fibre composite plate over the range of $0.1 \mathrm{MHz}-10 \mathrm{GHz}$ is shown in Fig.1., where the effective conductivity in an averaged sense (also called the bulk conductivity) is assumed to be $15 \mathrm{kS} / \mathrm{m}$. As can be seen from the figure, the penetration depth at $300 \mathrm{MHz}$ is well below $0.25 \mathrm{~mm}$, which is only two times larger than the thickness of a single layer (e.g. $0.125 \mathrm{~mm}$ ).

\section{WELL-ESTABLISHED RF NDT METHODS FOR CFRP COMPOSITES}

\section{A. Introduction}

Based on the detection mechanism, the RF NDT methods can be classified into four groups: electromagnetic induction methods, resonance methods, RF-based thermography and RF wave propagation method. The induction methods are primarily based on the Faraday's principle of the electromagnetic induction. While, the resonance methods mainly transform the defect information into the variation of the resonance frequency in the resonant circuit. The hybrid thermography methods are based on the conductive characteristic of the CFRP. In RF wave propagation method, the CFRP acts as a component of the transmission line or antenna. The mechanisms and applications of each kind will be demonstrated in detail. Here, the magnetic method, one kind of the RF NDT methods, is not mentioned, as it is confined to ferromagnetic and ferromagnetic materials [6].

\section{B. Electromagnetic induction methods}

\section{Eddy current technique (ECT)}

In Eddy current testing, a probe is excited with a sinusoidal alternating current (AC) to induce current in the conductive material, according to the Faraday's law. As shown in Fig.2.a), for the isotropic conductors, these induced circular current loops are called eddy currents. The impedance of the coil will be changed if there is some discontinuity in the conductivity distribution.

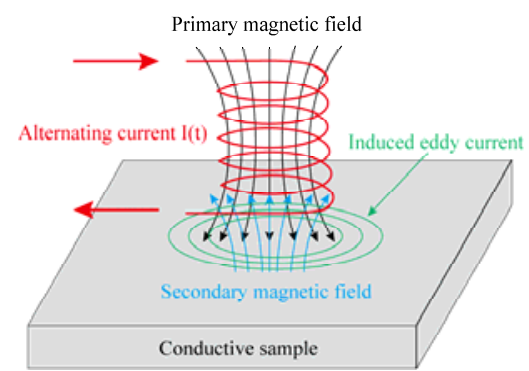

a)

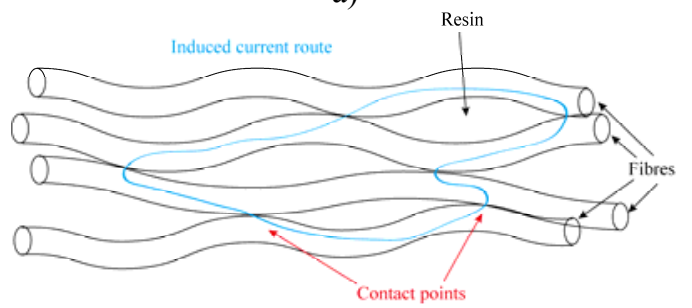

b)

Fig.2. Induced currents in conductive materials a) isotropic materials b) CFRP materials. 
However, in the present case, the induced currents are stretched in the direction of the high conductivity [7], i.e. the fibre direction, which is illustrated in Fig.2.b). The currents flow along fibres and from one fibre to another at the contact points. This special phenomenon has been confirmed by the finite element modelling [8]. Hence, precisely, the induced currents with the random shape of the current path in CFRP composites could not be grouped into the eddy currents. Nevertheless, the eddy current technique can still be employed for the detection of damage in CFRP composites, as long as the defect can be reflected in the change of the impedance measured by the impedance analyser.

The eddy current method is widely used for the detection of corrosion and cracks, and measurement of thickness and conductivity for metals [9]-[11]. However, it should be noted that ECT is not as mature for carbon-fibre composites as it is mainly for metals [12]. Mook et al. [13] used special static and rotary eddy current probes made of coils and ferrite cores to detect the fibre orientation, local defects like fibre breakage, resin rich zones, delamination and impact damage. The resultant image characterised the shape of the damaged zone after impact with an energy of 5J. Recently, a one dimensional and two dimensional low frequency probe with a high resolution of about $1 \mathrm{~mm}$ were also developed [14]. The probe could be used to detect surface and hidden defects in flat or even curved objects. Yin et al. [15] employed a circular air-cored coil to estimate the effective conductivity of a CFRP panel. It was found that the conductivity value was approximately inversely proportional to the peak frequency of the imaginary inductance. Koyama et al. [16], [17] detected purposely produced impact defects on a CFRP panel using an eddy current theta probe. The low impact energy of $0.25 \mathrm{~J}$ was detected. The correlation between the phase of the signal and the impact energy level was also found.

\section{Microwave open-ended waveguide imaging}

a) Mechanism

The microwave frequency extends from $300 \mathrm{MHz}$ to $300 \mathrm{GHz}$ with the corresponding wavelengths from $1 \mathrm{~m}$ to $1 \mathrm{~mm}$, respectively. In the test, the electromagnetic wave radiates from an open-ended waveguide or horn antenna to the specimen under test. Same as the ECT method, current can also be induced in the conductive sample by the microwave signals. The information of the cracks or dents on the surface is revealed by the attenuation/phase images of the reflection coefficient $\left(\mathrm{S}_{11}\right)$, which can be acquired from a vector network analyser (VNA).

The safety precaution is not needed since the power of the signal is relatively low (in the few milliwatts range). Various sizes of commercially available open-ended waveguides or horns are ready for use. The higher the operating frequency, the smaller the waveguide size would be. It is worth pointing out that there is a compromise between the penetration and spatial resolution, as the spatial resolution is highly dependent on the waveguide size [18]. The $\mathrm{X}$ band (8-12 GHz), Ku band (12-18 GHz), K band (18$26.5 \mathrm{GHz})$ and $\mathrm{Ka}$ band $(26.5-40 \mathrm{GHz})$ were recommended for NDT [19].

\section{b) Applications}

Akuthota et al. [20] applied the open-ended waveguide to detect the disbonds and delaminations between the CFRP composite laminate and the concrete substrate. They pointed out that the operating frequency and standoff distance should be chosen optimally (or near optimally) so that the measurement can be sensitive to the presence of a disbond. The smallest disbonded regions that could be detected at 10 and $24 \mathrm{GHz}$ were $20 \mathrm{~mm}$ by $5 \mathrm{~mm}$.

Kharkovsky et.al [21] employed the waveguide to detect fibre breakage and determine the fibre orientation in the CFRP patches. It was suggested that parallel orientation of the electric field polarisation in the waveguide with respect to fibre orientation was optimal for fibre breakage detection. In the test, a small breakage with dimensions of $0.2 \mathrm{~mm}$ by $1 \mathrm{~mm}$ was detected. The determination of fibre orientation was investigated by varying the angle between fibre direction and signal polarisation. Further, they proposed a near-field microwave inspection system consisting of a dualpolarised open-ended square waveguide probe [22]. The system automatically removed the influence of undesired standoff distance variations due to the surface roughness.

Yang et al. [23] detected the impact damage in CFRP specimens by using a horn antenna with the frequency range of $65-67 \mathrm{GHz}$. In the test, the E-field direction was parallel to the carbon fibre direction so that the dent on the surface was easily distinguished. The damage caused by the impact energy of $13.21 \mathrm{~J}$ and $8.89 \mathrm{~J}$ was reported to be detectable. The edge detection image processing technique was applied in order to obtain a more nature image.

\section{Couple spiral inductors (CSI)}

Recently, a new kind of the RF NDT sensor, i.e. coupled spiral inductors (CSI) [24], [25] was proposed. The planar spiral inductors are fabricated on a printed circuit board (PCB), as shown in Fig.3. The principle of this detection is based on the measurement of the transmitted energy from the primary coil to the secondary coil when placed above the CFRP composite structures. The sensor operates at higher frequencies (10-500 MHz), where the thickness of the composite is comparable with the skin depth. In the detection of the crack defect, it was shown that the shape of the crack provided by the CSI sensor was better than the ultrasonic testing [26].

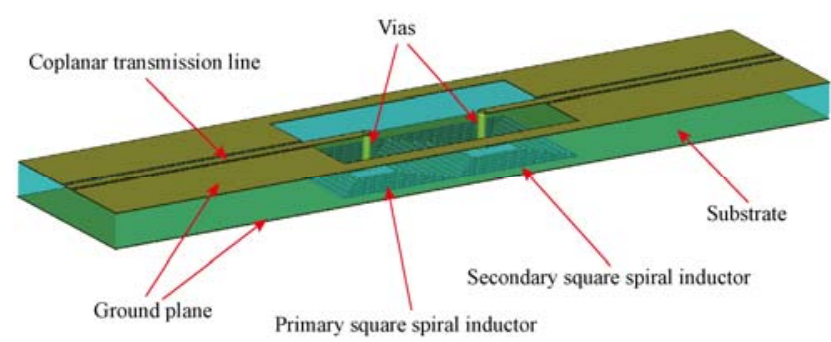

Fig.3. Perspective view of the CSI sensor. 


\section{Resonance methods}

A typical type of the resonance method is near-field scanning microwave microscopy (NSMM), which is generally composed of a resonant cavity and a sharp tip. As shown in Fig.4., only evanescent microwaves are emitted from the tip [27]. When the probe is kept at a fixed standoff distance, defects or conductivity discontinuity on the surface of the sample would affect the resonance frequency of the cavity. Subsequently, a surface contour plot of the resonance frequency could be produced, which indirectly indicates the unevenness or material discontinuity of the surface. The sharper the tip size is, the higher the spatial resolution that would be obtained. While, it should be noted that the penetration offered by this method is poor for carbon fibre materials due to the near-field feature.

The NSMM is primarily suited to map the conductivity of metallic lines on dielectric materials and PCBs [28], [29]. Valiente et al. [30] developed a new type of a microwave closed coaxial resonant cavity coupled to a tapered coplanar waveguide $(\mathrm{CPW})$ probing tip, and applied this profiler to detect the BVID on a carbon-fibre composite plate.

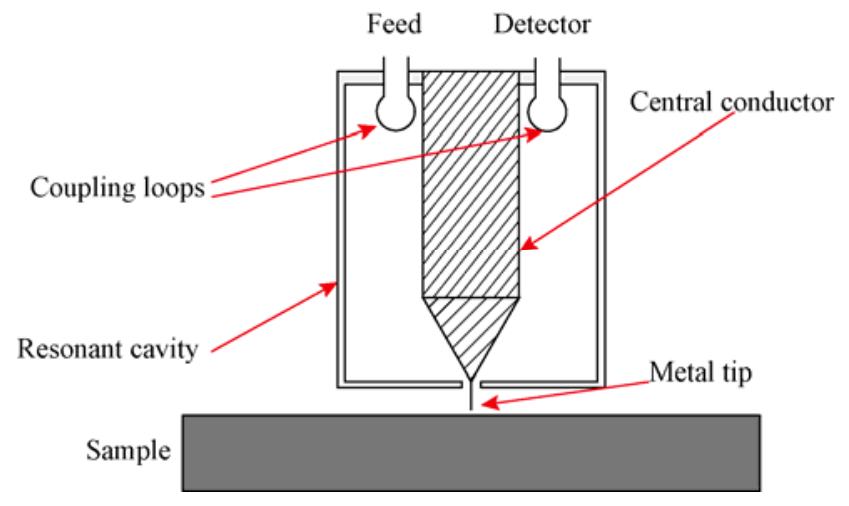

Fig.4. Schematic diagram of the near-field scanning microwave microscope.

\section{RF-based thermography methods}

\section{Pulsed eddy current (PEC) thermography}

The pulsed eddy current thermography combing PEC and thermography was developed for damage detection, which provided a fast and efficient method [31]. Any change in the microstructure of the CFRP composites could locally change the electrical conductivity tensor of the medium. Thus, by applying electric potential difference, the temperature of the medium would rise due to the Joule effect. Changes in the induced current flows would be revealed by an infrared (IR) camera. The pulsed excitation provides a low frequency spectrum, which subsequently offers a greater penetration depth than the eddy current technique [32]. Tian and his colleagues [33]-[35] successfully employed the pulsed eddy current thermography to detect both surface cracks and lowenergy impact damage.

\section{Microwave thermography}

Similar to the PEC technique, microwaves can also be used as a heat source for thermography. Foudazi [36] utilised the microwave energy to heat the region of interest, and then measured the thermal surface. It was shown that the delamination in the CFRP sample was visible in the thermal image of the surface under the microwave illumination of $50 \mathrm{~W}$ at $2.4 \mathrm{GHz}$. Lee et al. [37] proposed a noncontact and non-destructive microwave probe pumping technique. In this method, a coaxial probe was closely positioned on the backside of the sample. The pumped microwave E-field distribution was scanned by a near-field microwave microscope, and the $\mathrm{H}$-field distribution was obtained by an IR camera. The electrical defect can be detected from the anisotropic field distribution around the pumping probe.

\section{E. Methods based on RF wave propagation}

Owing to the conductive characteristic of the CFRP structure, the NDT methods using the transmission line and antenna theory have been proposed. In Todoroki's setup [38], a typical microstrip line was made with the CFRP sample as the ground plane. The information of the defect on the surface was reflected in the time domain response of the transmission line. Matsuzaki [39] used two woven CFRP laminates to build a dipole antenna. The damaged sample changed the antenna properties.

\section{EXPERIMENTAL RESULTS}

An example of the BVID detection by three abovementioned RF methods is given. The BVID on a $4 \mathrm{~mm}$ thick CFRP plate illustrated in Fig.5.a) was induced by a dropweight impact of $20 \mathrm{~J}$ energy. The diameter and depth of the dent observed using an optical microscope are approximately $3.85 \mathrm{~mm}$ and $44.3 \mu \mathrm{m}$, respectively. The dent could not be readily found during general visual inspection using typical lighting conditions.

\section{A. Open-ended waveguide imaging}

Here, a $\mathrm{K}$ band rectangular waveguide adapter with the inner dimensions of $10.70 \mathrm{~mm} \times 4.30 \mathrm{~mm}$ is used in the test. A 2D scanning is conducted with the step size of $530 \mu \mathrm{m}$, the standoff distance of $10 \mathrm{~mm}$ and the scanned area of $31.75 \mathrm{~mm} \times 20.64 \mathrm{~mm}$. Fig.5.b) shows the magnitude distribution of the reflection coefficient $\left|\mathrm{S}_{11}\right|$ at $18.5 \mathrm{GHz}$. The dent can still be identified, while the shape of the dent is slightly oval. The image distortion is primarily due to the intrinsic limited resolution of the imaging that is dependent on the waveguide dimensions [18].

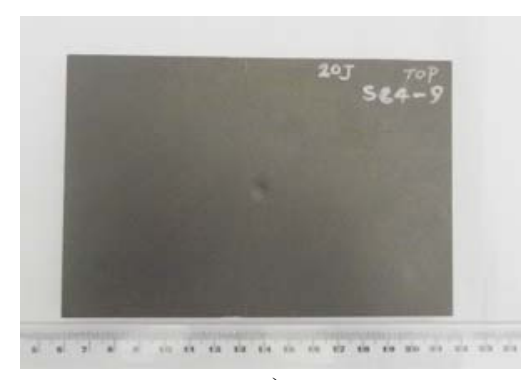

a) 


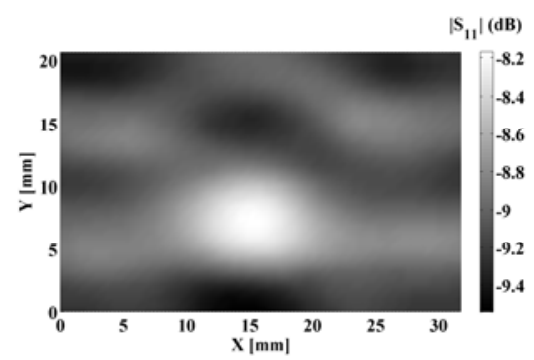

b)

Fig.5. a) CFRP composite plate with BVID

b) image by the open-ended waveguide imaging.

\section{B. CSI sensor}

The experimental setup is schematically illustrated in Fig.6.a). The outer diameter of each spiral coil is $6 \mathrm{~mm}$ [40]. The sensor is mounted on the X-Y-Z scanning stage and connected to a VNA by two coaxial cables. The computer is connected to the VNA and the PIC18C452 Microchip ${ }^{\circledR}$ microcontroller for data acquisition and precise movement control, respectively [41]. A 2D raster scanning is performed with the step size of $381 \mu \mathrm{m}$. The image of the magnitude of transmission coefficient $\left|\mathrm{S}_{21}\right|$ is shown in Fig.6.b). The white area showing higher magnitudes evidently indicates the presence and location of the dent.

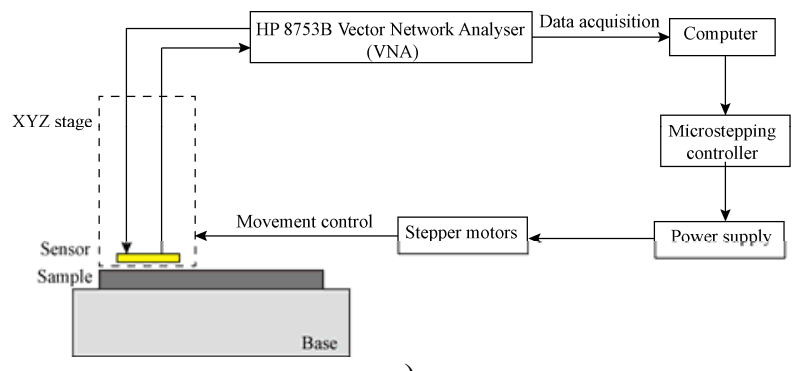

a)

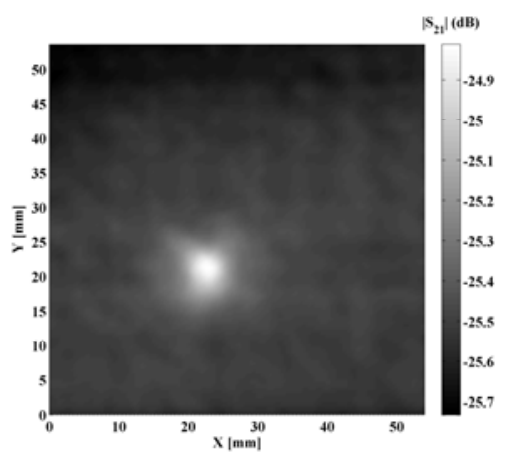

b)

Fig.6. a) Experimental setup b) $\left|\mathrm{S}_{21}\right|$ at $300 \mathrm{MHz}$.

\section{Near-field scanning microwave microscopy}

The near-field microwave profiler [30] developed in the University of Manchester was utilised. The dimensions of the tip are $600 \mu \mathrm{m} \times 4.30 \mathrm{~mm}$. The probe is connected to a Marconi 6200A scalar network analyser. The 2D scanning was conducted over the sample with the standoff distance of $100 \mu \mathrm{m}$ and the step size of $280 \mu \mathrm{m}$. As presented in Fig.7.b), the extent of the impact damage is clearly defined by the resonance frequency profiling. In addition, the symmetric and circular damage shape demonstrates better image quality than the open-ended waveguide imaging. However, it should be noted that the point-scanning process of the microwave microscopy is time-consuming.

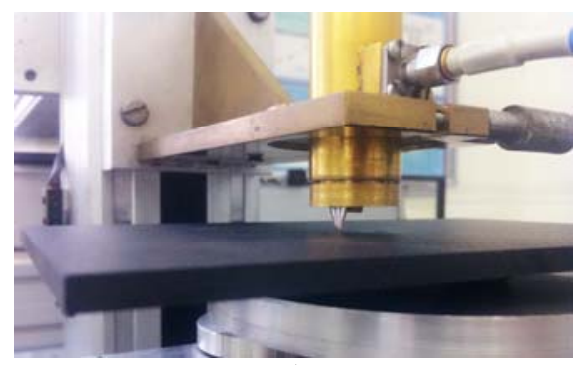

a)

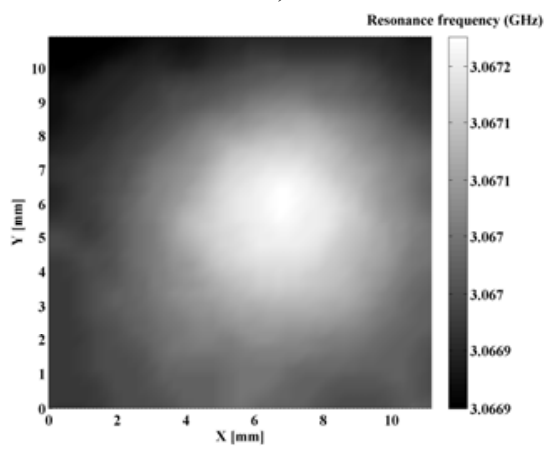

b)

Fig.7. a) The experimental setup b) image of the resonance frequency.

\section{DISCUSSIONS ON THE DEVELOPMENT OF NDT METHODS FOR INDUSTRIAL APPLICATIONS}

\section{A. State-of-the-art industrial radio frequency CFRP inspection}

In recent years, automated scanning has received considerable attention in industry. The numerically controlled robotic arm can be adopted to scan over the surface of aircraft structures. Heuer et al. [42] introduced the high frequency $(3 \mathrm{MHz}-30 \mathrm{MHz}$ ) eddy current (HFEC) technique into the value chain of CFRP composites, from fibre bundle over the fabric/prepreg and preform stage up to components and its life time. A maximum speed of $300 \mathrm{~mm} / \mathrm{sec}$ at a sampling rate of 3000 samples per second can be achieved. The high resolution technology has been integrated into a fully automated system for research. It was shown that the texture and waviness can be observed from the images. The depth of defects, infiltration and curing could be well characterised. Local area weight and carbon fibre volume content were determined from the signal amplitude.

Gabler et al. [43] extended ECT to imaging and investigation of insulating samples. In this case, the complex permittivity of the material influenced the complex impedance. The permittivity change during cure and defects in the epoxy resin L20 were captured by an industrial HFEC device with a coil diameter of $0.7 \mathrm{~mm}$ (allowing a high spatial resolution). This methodology could be applied to the characterisation of CFRP composites. 
Salski et al. [44] developed a portable automated scanner for inspection of CFRP composites. An array of radio frequency inductive sensors (i.e. CSI sensor) were mounted on a flexible arm and vacuum sucks were utilised to maintain mechanical stability. Intentionally produced holes, bubbles, cracks and delamination in both flat and curved CFRP panels were successfully detected.

\section{B. Three-dimensional imaging}

Two dimensional images provided by the RF NDT methods are not enough for the evaluation of some damage types. For example, for the impact damage detection, most work was solely on the identification of the existence of the dent on the surface. However, the impact damage on the surface is less severe than that underneath, as the damage spreads through the thickness and the delamination is enlarged extensively.

Theoretically, three-dimensional imaging is possible for the induction methods using multi-frequency inspection. When high frequencies are adopted, the results will only apply to the top few plies below the surface. With lower frequencies, the penetration depth will be significantly increased. Similar to the ultrasonic testing, the 2D images of all the inspection frequencies will go through thresholding, filtering, slicing and stacking in the $3 \mathrm{D}$ reconstruction procedure.

\section{Development of PCB-type sensors}

The CSI sensor fabricated on a common PCB board shows high effectiveness and cost-efficiency. Hence, other types of microwave PCB sensors could have the similar potential for sensing. The available configurations are split-ring resonator (SRR) [45], complementary split-ring resonator (CSRR) [46], double-sided spiral split-ring resonator (DSS-SRR) [47]. Recently, Iervolino et al. [48] proposed a passive PCB sensor with a planar spiral inductor for wireless and wired monitoring. Very promising capabilities were shown in the detection of holes and impact damage.

\section{Short-range imaging technique}

As existing RF NDT methods all belong to the near-field techniques, the standoff distance in these methods limits its application in field to certain extent. For the aircraft industry, the visual inspection for initial impact damage detection is likely to continue due to the cost and time associated with applying other NDE procedures over the full surface of a structure [49]. However, the accuracy of visual inspection is highly dependent on the inspector's experience and the light conditions. Therefore, a more efficient and effective NDT method is highly demanded.

Recently, the ultra-wideband (UWB) technology is starting to receive researchers' attention due to its intrinsic advantages of imaging [50]. Gubinelli et al. [51] first introduced the UWB technique to the detection of carbon fibre composites. The through-thickness hole with the diameter of $3 \mathrm{~mm}$ was accurately detected. In the test, the radar-to-sample distance was $40 \mathrm{~cm}$, which was significant compared with the other methods mentioned above.
Therefore, for the UWB approach, it is possible to provide a fast, cost-efficient, low power and long-distance damage detection for carbon fibre composite structures, which could be an alternative approach other than the current visual inspection in everyday routine check, especially at night.

\section{E. RFID-based NDT method}

The active radio frequency identification technology (RFID) with the capability of remote inspection and longterm structural health monitoring has also attracted extensive attention [52], [53]. Each RFID tag contains an integrated circuit (IC) chip and an antenna encapsulated together with the help of suitable packaging. As shown in Fig.8., the integrated circuit of the tag is made up of the impedance matching network, energy harvesting system, and microcontroller. In this test, a hand-held reader transmits a RF signal to the tag, and the small dipole antenna in the tag harvests the RF energy. Consequently, the integrated circuit (IC) in the tag is energised. Then the interaction between the tag and the sample, like the electromagnetic induction or guided elastic waves (Lamb waves), could take place. Finally, the defect information is transferred from the tag antenna to the detector by backscattering. The tags can be attached on the positions of interest.

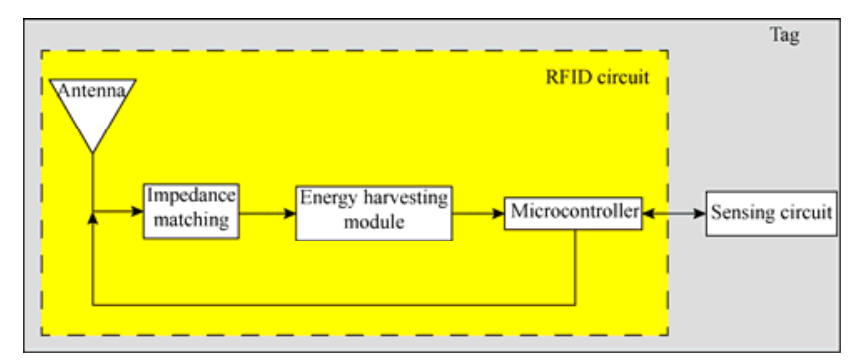

Fig.8. Block diagram of each component in a RFID tag for sensing.

Zhong et al. [52] demonstrated an integrated sensing system for large-area impact damage detection in composite materials. A guided wave sensor as a tag was embedded in the panel. $10 \mathrm{~J}$ impact damage was successfully detected. So far, to the best knowledge of the authors, little work is done on the damage detection in CFRP composites by combining the RFID technique with RF NDT methods. Considering the sensors in all the RF NDT methods, the PCB-type sensors have the potential for this objective, as its planar characteristic could be readily fabricated as a tag using the flexible PCB manufacturing technique.

\section{CONCLUSION}

This paper has presented an overview of the progress made in the application of RF NDT methods for carbonfibre composites. First, the anisotropic characteristic of the conductivity tenor of the carbon fibre composites has been revealed. Special attention should be paid to the relationship between the operating frequency and the penetration depth of the RF signal. The depth is inversely proportional to the square root of the frequency. 
The existing RF NDT methods for carbon fibre composites have been summarised into four main categories, which are electromagnetic induction methods, resonance methods, RFbased thermography and RF wave propagation methods. The mechanism, applications and limitations of each method have been presented in detail, which offers a comprehensive guidance for the selection of a suitable RF NDT method. An example of impact damage detection using the openended waveguide imaging, coupled spiral inductors, and near-field microwave microscopy have been well demonstrated.

Some suggestions on the future development of the RF NDT methods for industrial applications have been given. Specifically, the NDT methods can be integrated into a fully automated system, and 3D imaging of the electromagnetic induction methods could be possible using multi-frequency inspection. PCB sensor with other configurations can be employed. Two types of far-field NDT methods (UWB imaging and RFID-based NDT) have been proposed, both of which show the advantages of long-distance, low power, rapid detection and easy operation.

\section{ACKNOWLEDGMENT}

This work was financially supported by Dean's Doctoral Scholar Award of School of Materials, The University of Manchester. The first author would like to thank Prof. Constantinos Soutis and Dr. Arthur Haigh for guidance.

\section{REFERENCES}

[1] Soutis, C. (2005). Carbon fiber reinforced plastics in aircraft construction. Materials Science and Engineering A, 412 (1-2), 171-176.

[2] Zhang, J., Shi, C., Ma, Y., Han, X., Li, W., Chang, T., Wei, D., Du, C., Cui, H.L. (2015). Spectroscopic study of terahertz reflection and transmission properties of carbon-fiber-reinforced plastic composites. Optical Engineering, 54 (5), 054106.

[3] Pozar, D.M. (2009). Microwave Engineering. John Wiley \& Sons.

[4] Tse, K.W., Moyer, C.A., Arajs, S. (1981). Electrical conductivity of graphite fiber-epoxy resin composites. Materials Science and Engineering, 49 (1), 41-46.

[5] Weber, M., Kamal, M.R. (1997). Estimation of the volume resistivity of electrically conductive composites. Polymer Composites, 18 (6), 711-725.

[6] Blitz, J. (1997). Electrical and Magnetic Methods of Non-Destructive Testing. Springer.

[7] Menana, H., Féliachi, M. (2010). Modeling the response of a rotating eddy current sensor for the characterization of carbon fiber reinforced composites. The European Physical Journal Applied Physics, 52 (2), 23304.

[8] Cacciola, M., Calcagno, S., Megali, G. (2009). Eddy current modeling in composite materials. PIERS Online, 5 (6), 591-95.

[9] Yin, W., Peyton, A.J., Dickinson, S.J. (2004). Simultaneous measurement of distance and thickness of a thin metal plate with an electromagnetic sensor using a simplified model. IEEE Transactions on Instrumentation and Measurement, 53 (4), 1335-1338.
[10] Moulder, J.C., Uzal, E., Rose, J.H. (1992). Thickness and conductivity of metallic layers from eddy current measurements. Review of Scientific Instruments, 63 (6), 3455-3465.

[11] Yin, W., Peyton, A.J. (2006). A planar EMT system for the detection of faults on thin metallic plates. Measurement Science and Technology, 17 (8), 21302035.

[12] Staszewski, W., Tomlinson, G., Boller, C. (2004). Health Monitoring of Aerospace Structures Smart Sensor Technologies and Signal Processing. Wiley.

[13] Mook, G., Lange, R., Koeser, O. (2001). Nondestructive characterisation of carbon-fibre-reinforced plastics by means of eddy-currents. Composites Science and Technology, 61 (6), 865-873.

[14] Mook, G., Simonin, Y. (2014). Eddy current imaging using array probes. In 11th European Conference on Non-Destructive Testing (ECNDT 2014), 6-14 October 2014, Prague, Czech Republic.

[15] Yin, W., Withers, P.J., Sharma, U., Peyton, A.J. (2009). Noncontact characterization of carbon-fiberreinforced plastics using multifrequency eddy current sensors. IEEE Transactions on Instrumentation and Measurement, 58 (3), 738-743.

[16] Koyama, K., Hoshikawa, H., Kojima, G. (2013). Eddy current nondestructive testing for carbon fiberreinforced composites. Journal of Pressure Vessel Technology, 135 (4), 041501.

[17] Koyama, K., Hoshikawa, H., Hirano, T. (2011). Investigation of impact damage of carbon fiberreinforced plastic (CFRP) by eddy current nondestructive testing. In Smart Materials, Structures \& NDT in Aerospace: International Workshop, 2-4 November 2011, Montreal, Canada, 582-594.

[18] Li, Z., Haigh, A., Soutis, C., Gibson, A. (2014). Simulation for the impact damage detection in composites by using the near-field microwave waveguide imaging. In 53rd Annual Conference of the British Institute of Non-Destructive Testing (NDT 2014), 9-11 September 2014, Manchester, UK.

[19] Green, G.A., Campbell, P., Zoughi, R. (2004). An investigation into the potential of microwave NDE for maritime application. In 16th World Conference of Non-Destructive Testing, 30 August - 3 September 2004, Montreal, Canada.

[20] Akuthota, B., Hughes, D., Zoughi, R., Myers, J., Nanni, A. (2004). Near-field microwave detection of disbond in carbon fiber reinforced polymer composites used for strengthening cement-based structures and disbond repair verification. Journal of Materials in Civil Engineering, 16 (6), 540-546.

[21] Kharkovsky, S., Zoughi, R. (2005). Application of near-field microwave and millimeter wave nondestructive testing for evaluation of fiber breakage and orientation evaluation in CFRP composite patches. AIP Conference Proceedings, 760, 554-561.

[22] Kharkovsky, S., Ryley, A.C., Stephen, V., Zoughi, R. (2008). Dual-polarized near-field microwave reflectometer for noninvasive inspection of carbon fiber reinforced polymer-strengthened structures. IEEE Transactions on Instrumentation and Measurement, 57 (1), 168-175. 
[23] Yang, S.H., Kim, K.B., Oh, H.G., Kang, J.S. (2013). Non-contact detection of impact damage in CFRP composites using millimeter-wave reflection and considering carbon fiber direction. NDT \& $E$ International, 57, 45-51.

[24] Salski, B., Gwarek, W., Korpas, P. (2014). Electromagnetic inspection of carbon-fiber-reinforced polymer composites with coupled spiral inductors. IEEE Transactions on Microwave Theory and Techniques, 62 (7), 1535-1544.

[25] Salski, B., Gwarek, W., Korpas, P. (2014). Nondestructive testing of carbon-fiber-reinforced polymer composites with coupled spiral inductors. In IEEE MTT-S International Microwave Symposium (IMS2014), 1-6 June 2014. IEEE, 1-4.

[26] Salski, B., Gwarek, W., Korpas, P., Reszewicz, S., Chong, A.Y.B., Theodorakeas, P., Hatziioannidis, I., et al. (2015). Non-destructive testing of carbon-fibrereinforced polymer materials with a radio-frequency inductive sensor. Composite Structures, 122 (4), 104 122.

[27] Tabib, A.M, Shoemaker, N.S., Harris, S. (1993). Nondestructive characterization of materials by evanescent microwaves. Measurement Science and Technology, 4 (5), 583-590.

[28] Wei, T., Xiang, X.D., Wallace-Freedman, W.G., Schultz, P.G. (1996). Scanning tip microwave nearfield microscope. Applied Physics Letters, 68 (24), 3506-3508.

[29] Zhang, Q. (2006). Near-field scanning microwave microscopy and its applications in characterization of dielectric materials. Doctoral Dissertation, University of Notre Dame, Indiana, United States.

[30] Valiente-Montano, L.A. (2007). Scanning near-field microwave profiler. University of Manchester, Manchester, United Kingdom.

[31] Riegert, G., Zweschper, T., Busse, G. (2004). Lockin thermography with eddy current excitation. Quantitative InfraRed Thermography Journal, 1 (1), 21-32.

[32] Lebrun, B., Jayet, Y., Baboux, J.C. (1997). Pulsed eddy current signal analysis, application to the experimental detection and characterization of deep flaws in highly conductive materials. NDT \& E International, 30 (3), 163-170.

[33] He, Y., Tian, G., Pan, M., Chen, D. (2014). Impact evaluation in carbon fiber reinforced plastic (CFRP) laminates using eddy current pulsed thermography. Composite Structures, 109, 1-7.

[34] Pan, M., He, Y., Tian, G., Pan, M., Chen, D., Luo, F. (2012). Defect characterisation using pulsed eddy current thermography under transmission mode and NDT applications. NDT \& E International, 52, 28-36.

[35] Cheng, L., Tian, G. (2011). Surface crack detection for carbon fiber reinforced plastic (CFRP) materials using pulsed eddy current thermography. IEEE Sensors Journal, 11 (12), 3261-3268.
[36] Foudazi, A., Donnell, K.M., Ghasr, M.T. (2014). Application of active microwave thermography to delamination detection. In IEEE International Instrumentation and Measurement Technology Conference (I2MTC) Proceedings, 12-15 May 2014. IEEE, 1567-1571.

[37] Lee, H., Galstyan, O., Babajanyan, A., Friedman, B., Berthiau, G., Kim, J., Han, D.S., Lee, K. (2015). Characterization of anisotropic electrical conductivity of carbon fiber composite materials by a microwave probe pumping technique. Journal of Composite Materials, August 2015, 1-6.

[38] Todoroki, A., Ohara, K., Mizutani, Y., Suzuki, Y., Matsuzaki, R. (2015). Lightning strike damage detection at a fastener using self-Sensing TDR of composite plate. Composite Structures, 132, 11051112.

[39] Matsuzaki, R., Melnykowycz, M., Todoroki, A. (2009). Antenna/sensor multifunctional composites for the wireless detection of damage. Composites Science and Technology, 69 (15-16), 2507-2513.

[40] Li, Z., Haigh, A., Soutis, C., Gibson, A., Sloan, R., Karimian, N. (2015). Damage evaluation of carbonfibre reinforced polymer composites using electromagnetic coupled spiral inductors. Advanced Composites Letters, 24 (3), 44-47.

[41] Li, Z., Haigh, A., Soutis, C., Gibson, A., Sloan, R., Karimian, N. (2016). Detection and evaluation of damage in aircraft composites using electromagnetically coupled inductors. Composite Structures, 140, 252-261.

[42] Heuer, H., Schulze, M., Pooch, M., Gabler, S., Nocke, A., Bardl, G., et al. (2015). Review on quality assurance along the CFRP value chain-nondestructive testing of fabrics, preforms and CFRP by HF radio wave techniques. Composites Part B: Engineering, 77, 494-501.

[43] Gabler, S., Heuer, H., Heinrich, G. (2015). Measuring and imaging permittivity of insulators using highfrequency eddy-current devices. IEEE Transactions on Instrumentation and Measurement, 64, 2227-2238.

[44] Salski, B., Gwarek, W., Kopyt, P., Theodorakeas, P., Hatziioannidis, I., Koui, M., et al. (2015). Portable automated radio-frequency scanner for non-destructive testing of carbon-fibre-reinforced polymer composites. In 6th International Conference on Emerging Technologies in Nondestructive Testing, 27-29 May 2015. CRC Press, 267-273.

[45] Albishi, A.M., Boybay, M.S., Ramahi, O.M. (2012). Complementary split-ring resonator for crack detection in metallic surfaces. IEEE Microwave and Wireless Components Letters, 22 (6), 330-332.

[46] Albishi, A., Ramahi, O.M. (2014). Detection of surface and subsurface cracks in metallic and nonmetallic materials using a complementary split-ring resonator. Sensors, 14 (10), 19354-19370. 
[47] Benkhaoua, L., Benhabiles, M.T., Riabi, M.L. (2014). A miniaturized near-field sensor based on a doublesided spiral split-ring resonator for dielectric characterization. In IEEE MTT-S International Microwave Workshop Series on RF and Wireless Technologies for Biomedical and Healthcare Applications (IMWS-Bio), 8-10 December 2014. IEEE, $1-3$.

[48] Iervolino, O., Meo, M. (2016). A spiral passive electromagnetic sensor (SPES) for wireless and wired structural health monitoring. Measurement Science and Technology, 27 (4), 045601.

[49] U.S. Department of Defense. (2002). Composite Materials Handbook: Volume 3. Polymer Matrix Composites. Materials Usage, Design, and Analysis.

[50] Kidera, S., Sakamoto, T., Sato, T. (2010). Accurate UWB radar three-dimensional imaging algorithm for a complex boundary without range point connections. IEEE Transactions on Geoscience and Remote Sensing, 48 (4), 1993-2004.
[51] Gubinelli, S., Paolini, E., Giorgetti, A., Mazzotti, M., Andrea, R., Enrico, T., Marco, C. (2014). An ultrawideband radar approach to nondestructive testing. In IEEE International Conference on Ultra-WideBand (ICUWB), 1-3 September 2014. IEEE, 303-308.

[52] Zhong, C.H., Croxford, A.J., Wilcox, P.D. (2014). Remote inspection system for impact damage in large composite structure. Proceedings of the Royal Society A: Mathematical, Physical and Engineering Sciences, 471 (2175), 20140631.

[53] Alamin, M., Tian, G.Y., Andrews, A., Jackson, P. (2012). Corrosion detection using low-frequency RFID technology. Insight - Non-Destructive Testing and Condition Monitoring, 54 (2), 72-75.

Received October 26, 2015. Accepted March 24, 2016. 